\section{A response to the LENT score}

We would like to congratulate Clive et $a l^{1}$ on their contemporary data on survival in malignant pleural effusion. These data, particularly for lung cancer, will be invaluable for decision-making in cancer multidisciplinary meetings.

The LENT prognostic score (pleural fluid lactate dehydrogenase, Eastern Cooperative Oncology Group (ECOG) performance score (PS), neutrophil-tolymphocyte ratio and tumour type) is applied to unselected patients with malignant pleural effusion. Mesotheliomarelated pleural effusion would not necessarily indicate an advanced disease state, compared with, for example, urological malignancy. Did the authors consider grouping patients by availability of suitable treatments? Oestrogen receptor-positive breast cancer or haematological malignancy would be more likely to benefit from chemotherapy than lung cancer.

The authors demonstrate in their receiver operator curve analysis that the area under the curve was higher using the prognostic score than for ECOG performance status alone. If the data on haematological malignancy and mesothelioma are not included then malignant pleural effusion related to lung cancer would account for approximately $50 \%$ of the cohort used to develop the LENT score. Have the authors considered comparing the area under the curve for ECOG score and LENT score for lung cancer alone?

In our opinion, the most important conclusion from the paper is that the median survival of malignant pleural effusion in lung cancer remains extremely poor. This information should be considered by all oncologists and respiratory physicians encountering the disease and encourage prompt engagement with palliative care services.

James Murray, Richard Turner, Graham H Bothamley, Angshu Bhowmik

Department of Respiratory Medicine, Homerton University Hospital, London, UK

Correspondence to Dr James Murray, Department of Respiratory Medicine, Homerton University Hospital, Homerton Row, London E9 6SR, UK; jamesmurray@ doctors.org.uk, james.murray@homerton.nhs.uk

Contributors The first draft was completed by JM, and a first edit by RT. Final edits were done by GHB and $A B$.

Competing interests None.

Provenance and peer review Not commissioned; internally peer reviewed.

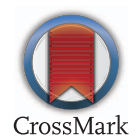

To cite Murray J, Turner R, Bothamley GH, et al. Thorax 2014;69:1144.

Received 21 August 2014

Accepted 4 September 2014

Published Online First 22 September 2014

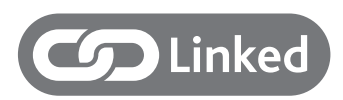

- http://dx.doi.org/10.1136/thoraxjnl-2014-205285

- http://dx.doi.org/10.1136/thoraxjnl-2014-206247

Thorax 2014;69:1144.

doi:10.1136/thoraxjnl-2014-206194

\section{REFERENCE}

1 Clive AO, Kahan BC, Hooper CE, et al. Predicting survival in malignant pleural effusion: development and validation of the LENT prognostic score. Thorax 2014;69:1098-104. 